\title{
Anopheles albitarsis Embryogenesis: Morphological Identification of Major Events
}

\author{
Adelaide Tardin Monnerat, Marcelo Pelajo Machado*, Bruno Silva Vale*, \\ Maurilio José Soares**, José Bento Pereira Lima***/****, Henrique Leonel Lenzi*, \\ Denise Valle $\mathrm{e}^{* * *} / * * * * /+$
}

\begin{abstract}
Departamento de Bioquímica e Biologia Molecular *Departamento de Patologia **Departamento de Ultra-estrutura e Biologia Celular ***Departamento de Entomologia, Instituto Oswaldo Cruz-Fiocruz, Av. Brasil 4365, 21045-900 Rio de Janeiro, RJ,

Brasil ****Laboratório de Entomologia, Instituto de Biologia do Exército, Rio de Janeiro, RJ, Brasil
\end{abstract}

Anopheles albitarsis embryogenesis was analyzed through confocal microscopy of clarified eggs. Using Drosophila melanogaster as reference system, the major morphogenetic events (blastoderm, gastrulation, germ band extension, germ band retraction, dorsal closure) were identified. The kinetics of early events is proportionally similar in both systems, but late movements (from germ band retraction on) progress slower in An. albitarsis. Major differences in An. albitarsis related to D. melanogaster were: (1) pole cells do not protrude from the blastoderm; (2) the mosquito embryo undergoes a $180^{\circ}$ rotation movement, along its longitudinal axis; (3) the head remains individualized throughout embryogenesis; (4) extraembryonary membranes surround the whole embryo. A novel kind of malaria control is under development and is based on the use of genetically modified mosquitoes. Phenotypic analysis of the embryonic development of mutants will be imposed as part of the evaluation of effectiveness and risk of employment of this strategy in the field. In order to accomplish this, knowledge of the wild type embryo is a prerequisite. Morphological studies will also serve as basis for subsequent development biology approaches.

Key words: Anopheles - malaria vector - embryo - development - mosquito

Nowadays, nearly $30 \%$ of the world population, mainly in tropical countries, is at risk of acquiring malaria, an endemic disease that kills 1-2 million people each year (Buttler et al. 1997, Morel 2000). Malaria is caused by protozoan parasites belonging to the genus Plasmodium which undergo an obligatory part of their life cycle inside a mosquito. A major obstacle to control of human malaria is the varied degree of resistance exhibited by Plasmodium strains and Anopheles wild populations to the presently available chemotherapics and insecticides, respectively (Greenwood 1997).

An alternative strategy to malaria vector control is presently under way and involves the construction of genetically modified mosquitoes, refractory to Plasmodium infections (Kidwell \& Ribeiro 1992, Crampton 1994, Buttler et al. 1997). Although most of the present studies aiming the construction of transgenic mosquitoes rely on molecular assays (Coates et al. 1998, Jasinskiene et al. 1998, Catteruccia et al. 2000), knowledge of the basic developmental biology of vectors (and of their embryogen-

This investigation received financial assistance from the UNDP/ World Bank/WHO Special Programme for Research and Training in Tropical Diseases, Conselho Nacional de Desenvolvimento Científico e Tecnológico, Fundação Carlos Chagas Filho de Amparo à Pesquisa do Estado do Rio de Janeiro and Fundação Oswaldo Cruz.

${ }^{+}$Corresponding author. Fax: +55-21-2573.4468. E-mail: dvalle@ioc.fiocruz.br

Received 22 October 2001

Accepted 28 January 2002 esis in particular) is also of fundamental importance when the establishment of transformants is concerned (Bate \& Arias 1993). In order to generate transformed lineages, exogenous DNA must be injected into embryos at a very specific position and time during their development (Miller et al. 1987).

It is expected that several mutants and transgenic lines will be obtained by the introduction and mobilization of transposable elements into Anopheles spp. Phenotypic analysis of these mutants is imposed as part of the evaluation of effectiveness and risk the use, in the field, of a vector control strategy based on transgenic mosquitoes. Since, as it occurs with the model system $D$. melanogaster, several mutants affecting viability are expected to be embryonic lethal (Bate \& Arias 1993), knowledge of the morphological alterations in embryos belonging to mutant mosquito lineages will be an important component in their phenotypic analysis. Furthermore, in cases where mutants are not available, the study of a gene's expression pattern in a wild type embryo can contribute to elucidate its function and, consequently, define its relevance for the viability (and control) of a defined organism.

It turns out that a systematic analysis of the embryonic development of wild type mosquitoes is important in order to accomplish exogenous DNA injections, phenotypic analysis of mutants and even to define the expression pattern of new genes. However, this has been a neglected issue: so far only embryos of a single Anopheles species have been submitted to a morphological analysis (An. maculipennis, Ivanova-Kazas 1949). Information on other mosquito embryos, mainly obtained in the 60's and 70's, is often scarce and incomplete. Among mosquitoes, mainly Culex and Aedes embryos have been investi- 
gated (Rosay 1959, Davis 1967, Guichard 1971, Raminani \& Cupp 1975, 1978).

In the present study we have identified, by comparison with $D$. melanogaster, the major morphological events occurring throughout the embryonic development of a neotropical malaria vector, An. (Nyssorhynchus) albitarsis. This corresponds to the first step towards a systematic morphological analysis of wild type Anopheles embryos aiming to contribute to the establishment of new vector control methods and to the further analysis of expression of different genes during development in these species.

\section{MATERIALS AND METHODS}

Insects - An. albitarsis sensu stricto females came from a free mating stable colony maintained in the laboratory since 1995 (Horosko et al. 1997), kept at $26^{\circ} \mathrm{C}$ and $80 \%$ r. h. Larvae were fed with powdered fish food (1:1 mixture of Tetramin Baby Fish Type L and Type E) and adults were constantly supplied with $10 \%$ sucrose solution. Females starved for 2-4 $\mathrm{h}$ were fed on guinea pigs in order to elicit eggs production. D. melanogaster embryos were obtained from wild type stocks kindly provided by Drs Ricardo Ramos and Antônio Bernardo Carvalho (Universidade Federal do Rio de Janeiro).

Mosquito eggs collection - Collection of the eggs was done at $2 \mathrm{~h}$ intervals, from egglaying to hatching. In order to overcome the crepuscular oviposition, typical of $A n$. albitarsis, some time points were collected according to the method described by Lanzara et al. (1988). This method consists in the induction of oviposition through removal of one wing from females that have been blood fed four days before. The mosquitoes were then placed individually in small plastic cups filled with dechlorinated water and maintained in the dark. After oviposition the females were removed and the eggs were kept in the plastic cups for defined periods of time. Collection of eggs for shorter periods of time was not possible due to the extreme sensitivity of An. albitarsis to manipulation.

Mosquito eggs clarification - Eggs chorion clarification (also corresponding to embryo development interruption) has been performed in small glass vials filled with $0.037 \mathrm{M}$ sodium chlorite plus $1.45 \mathrm{M}$ acetic acid, tightly closed and kept under gentle agitation, protected from light, at room temperature (Tripš 1970). The clarification procedure was monitored under a stereomicroscope, and varied from 42 to $66 \mathrm{~h}$. The eggs were then washed five times with phosphate buffered saline $\mathrm{pH} 7.5$ and wholemounted in slides in a 1:1 glycerol:phosphate buffered saline solution.

Mosquito embryo analysis - Embryos were visualized by confocal microscopy, performed with a Zeiss LSM 410 using a $\mathrm{He} / \mathrm{Ne}$ laser beam $(543 \mathrm{~nm})$. Autofluorescence signal was achieved with a LP 570 filter (Valle et al. 1999).

Drosophila embryos - Staged D. melanogaster embryos were submitted to the Forbes and Ingham (1993) protocol used to remove all eggshell layers. The embryos were then fixed for $1 \mathrm{~h}$ with $2.5 \%$ glutaraldehyde in $0.1 \mathrm{M}$ cacodylate buffer, $\mathrm{pH} 7.2$, washed in cacodylate buffer, post-fixed for $30 \mathrm{~min}$ with $1 \%$ osmium tetroxide in $0.1 \mathrm{M}$ cacodylate buffer, $\mathrm{pH} 7.2$, rinsed in buffer, dehydrated in acetone and critical point dried. The eggs were then adhered to scanning electron microscopy stubs covered with adhesive tape, coated with a $20 \mathrm{~nm}$ thick gold layer in a sputtering device and observed in a Zeiss DSM 940 scanning electron microscope (SEM).

\section{RESULTS}

Mosquito embryos are covered by an eggshell made by a compound exochorion (or "outer" chorion layer) and a homogeneous endochorion ("inner" chorion layer) (Hinton 1968, Valle et al. 1999, Monnerat et al. 1999). Eggshells are bright and soft at oviposition, but eggs of Anopheles, Culex and Aedes spp. soon turn dark and rigid (Clements 1992), a process that precludes the direct observation of the embryos. Darkening and hardening of eggshells are both consequence of sclerotization, a process occurring in the endochorion ( $\mathrm{Li} 1994)$. Use of the clarification protocol developed by Tripš (1970) allowed to remove the exochorion and to render the endochorion of An. albitarsis transparent, without affecting embryo morphological integrity. This enabled observation of the embryos development, carried out by confocal microscopy. Both the remaining endochorion and the embryos inside were fluorescent, enabling the morphological identification of the major morphogenetic movements occurring during embryogenesis through analysis of the reflected light.

In order to follow the convention adopted for the model system D. melanogaster, pictures are shown here with the anterior pole to the left and, unless otherwise indicated, the dorsal side facing upwards, as previously suggested (Bate \& Arias 1993, Valle et al. 1999). Structures and features appearing in the mosquito embryo are localized in terms of percent of egg length (EL), where zero is the posterior pole and the anterior pole corresponds to $100 \%$ (Bate \& Arias 1993). Staged D. melanogaster embryos were examined by SEM after removal of eggshell layers, and embryos at typical major developmental stages were included in some plates for comparison.

Blastoderm formation - Early D. melanogaster embryos display homogeneously distributed yolk granules; only the periphery of the embryo and a cytoplasmic island (energid) in the anterior third of the egg, surrounding the female pronucleus, are yolk-free. As cleavage divisions take place, each zygotic nucleus becomes surrounded by a cytoplasmic island. In D. melanogaster, the syncytial blastoderm takes place from $1 \mathrm{~h} 20^{\prime}$ to $2 \mathrm{~h} 10^{\prime}$ at $25^{\circ} \mathrm{C}$, when cellularization of the germ lineage, located at the posterior pole, occurs (Fig. 2A). The somatic cells are formed later ( $\left.2 \mathrm{~h} 10^{\prime}-2 \mathrm{~h} 50^{\prime}\right)$ by synchronous extension of membrane furrows along the embryo cortex (Bate \& Arias 1993, Campos-Ortega \& Hartenstein 1997), characterizing the cellular blastoderm (Fig. 3A).

Early An. albitarsis embryos occupy the whole egg, their cortical cytoplasm being adjacent to the eggshell. The anterior half of the embryo is larger than the posterior side. At $0-2 \mathrm{~h}$ after egglaying, several spherical autofluorescent dots of undefined nature are observed scattered throughout the embryo (Fig. 1). Rounded patches exhibiting less intense fluorescence are also visible. At 2-4 h after egglaying, nuclei have already reached 
the periphery and the yolk mass is concentrated in the embryo internal domain (Fig. 2B), a picture typical of dipteran eggs. Analysis of 2-4 h old embryos at higher magnification (Fig. 2C) confirmed the cortical position of nuclei but did not reveal any sign of cellularization, indicating that, at that time, embryos are in the syncytial blastoderm stage.

At 4-6 $\mathrm{h}$ after egglaying, the cellular limits are clearly visible at the An. albitarsis embryo cortex (Fig. 3B, C). Cells of two distinct sizes are observed: while cells with surface area of about $80 \mu \mathrm{m}^{2}$ are concentrated in the posterior pole, those measuring $20-40 \mu \mathrm{m}^{2}$ can be found in the rest of the embryo. These smaller cells correspond to the somatic lineage and will give rise to all body compartments. The larger cells are supposed to be the pole cells, precursors of the germ line. These morphological characteristics are typical of the cellular blastoderm stage.

Gastrulation - D. melanogaster early gastrulation is a short stage (10'), characterized by the invagination of mesoderm and endoderm and by the appearance of a cephalic furrow, at around 65\% EL (Fig. 4A, CamposOrtega \& Hartenstein 1997).

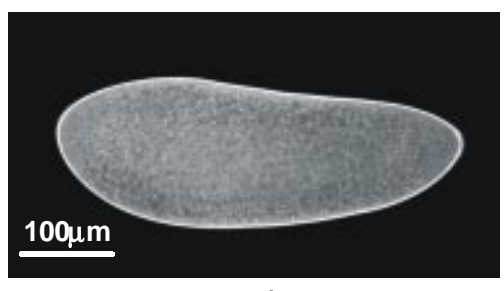

0-2 h

Fig. 1: Anopheles albitarsis preblastoderm ( $0-2 \mathrm{~h}$ old) embryo as viewed by confocal microscopy. Anterior pole to the left.

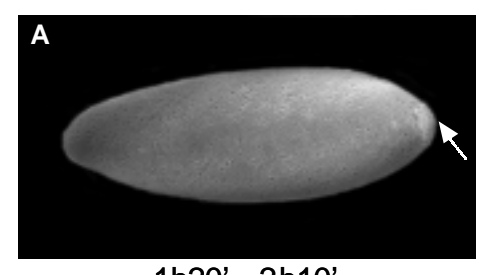

$1 h^{\prime} 0^{\prime}-2 h 10^{\prime}$
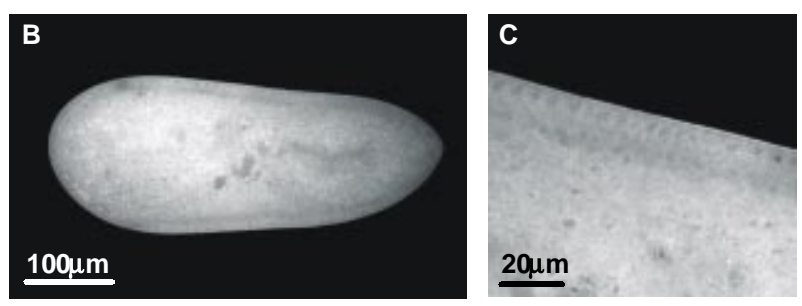

2-4 h

Fig. 2: syncytial blastoderm stage of a Drosophila melanogaster (A) and Anopheles albitarsis (B, C) embryo. A: scanning electron microscopy; B, C: confocal microscopy; A, B: whole embryos; C: detail of a cortical region of embryo shown in B. Numbers below A $\mathrm{B}$ and $\mathrm{C}$ indicate, respectively, the duration of the syncytial blastoderm in Drosophila embryos and the time elapsed since oviposition in Anopheles ones. In A, B, the anterior pole is turned to the left side.
In An. albitarsis, at 4-6 h after oviposition some embryos develop a lateral invagination at 70\% EL (compare panels A and B of Fig. 4, corresponding to D. melanogaster and An. albitarsis, respectively). This was interpreted as the first sign of gastrulation, typified by the formation of the cephalic furrow. In some cases a longitudinal ventral enlargement was detected in the trunk portion of the embryo that should correspond to the beginning of mesoderm invagination (visible in Drosophila, at the bottom of Fig. 4A).

Germ band extension - Germ band extension in Diptera is characterized by folding the trunk domain to the dorsal side of the embryo and its further progression towards the anterior portion, as illustrated in Fig. 5A. In $D$. melanogaster embryos, this stage is divided into a rapid early phase, when the germ band extends until $60 \% \mathrm{EL}$, in
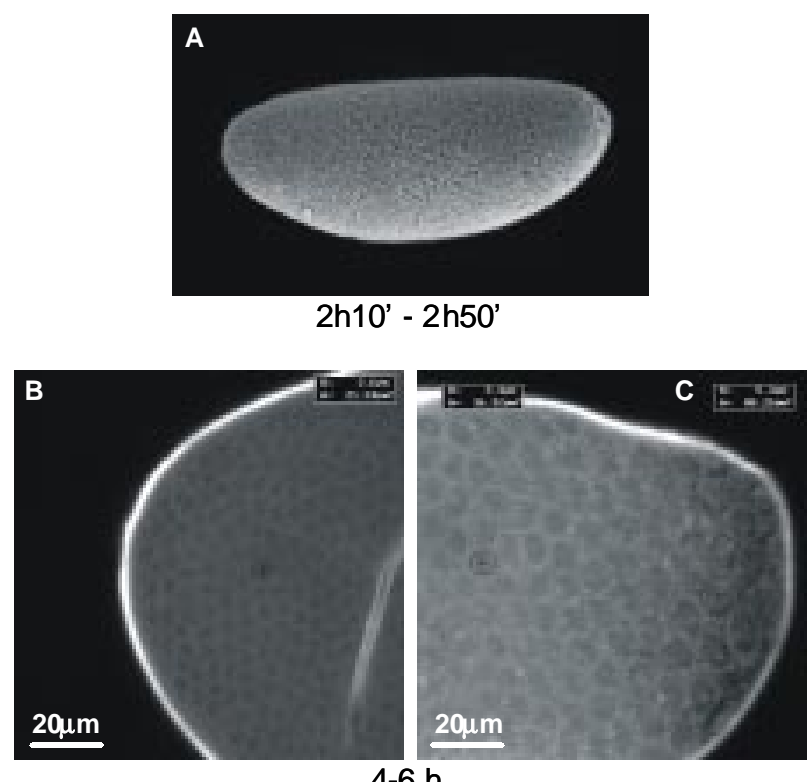

4-6 h

Fig. 3: cellular blastoderm stage of a Drosophila melanogaster (A) and an Anopheles albitarsis (B, C) embryo. A: scanning electron microscopy; B, C: confocal microscopy; A: whole embryo; B: detail of anterior pole; $\mathrm{C}$ : detail of posterior pole. $\mathrm{R}$ and $\mathrm{A}$ in panels $\mathrm{B}$ and $\mathrm{C}$ refer to the radius and surface area of the encircled cells $(\mathrm{R}$ $=2.6$ and $3.4 \mu \mathrm{m}$ and $\mathrm{A}=21.24$ and $36.32 \mu \mathrm{m}^{2}$ in $\mathrm{B}$ and $\mathrm{C}$, respectively). Numbers below each panel indicate the embryos' age, as stated in Fig. 2. In A, Drosophila embryo dorsal side faces upward and the anterior pole is turned to the left.
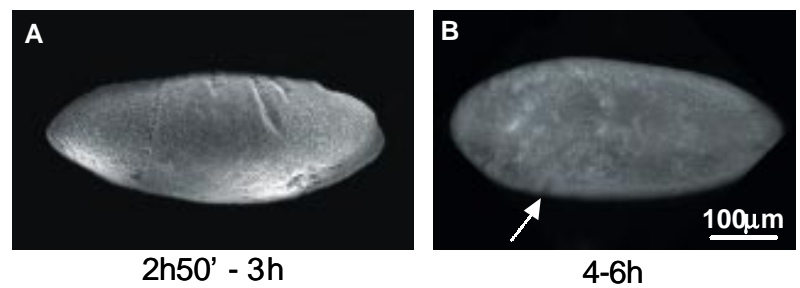

Fig. 4: gastrulation stage of a Drosophila melanogaster (A) and an Anopheles albitarsis (B) embryo. A: scanning electron microscopy; B: confocal microscopy. The Drosophila embryo is in a ventrolateral position while the An. albitarsis one is in a dorsal position. Numbers below panels as indicated in Fig. 2. Anterior pole to the left. 
$30 \mathrm{~min}$, and a slow phase, that requires additional $2 \mathrm{~h}$ to extend $15 \%$ further (up to $75 \%$ EL, Campos-Ortega \& Hartenstein 1997).

An. albitarsis germ band extension is first detectable around $8 \mathrm{~h}$ after egglaying. Fig. 5B shows a $6-8 \mathrm{~h}$ old embryo, in lateral position, where the germ band extends towards the anterior pole. A rate difference between the early and the late phases of germ band extension was also observed in this species: while 4-6 h old embryos are at cellular blastoderm or gastrulation (Figs 3, 4), 6-8 h old ones have already proceeded germ band extension until $60 \%$ EL (Fig. 5B). By contrast, the maximal germ band extension (70\% EL) takes another $2 \mathrm{~h}$ (8-10 h old embryos, Fig. 5C) to be accomplished.

The first external signs of segmentation appear at 10$12 \mathrm{~h}$ after egglaying, when the embryo is still at the maximal germ band extension stage (Fig. 5D). In opposition to Drosophila embryos, where segmentation is detected simultaneously in the whole body, in An. albitarsis the first external metameric units are initially observed only at the anterior region.

During germ band extension, the embryo starts to detach itself from the eggshell, a feature clearly visible at the end of this stage (10-12 h old embryos, Fig. 5D). In some cases the original egg shape is slightly altered, as a consequence of its softening by the clarification procedure.

Germ band retraction - After the complete extension of the germ band and appearance of the initial segmentation signs, the embryo starts the germ band retraction, a process that establishes the normal anatomical aspect of the larva (Fig. 6A). In An. albitarsis, germ band retraction is first detected at 14-16 h after egglaying (Fig. 6B). During this stage, the intersegmental furrows deepen, ren-

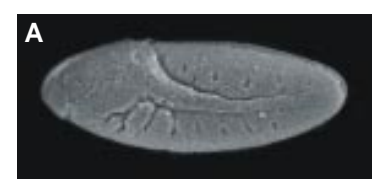

$3 \mathrm{~h}-7 \mathrm{~h} 20^{\prime}$

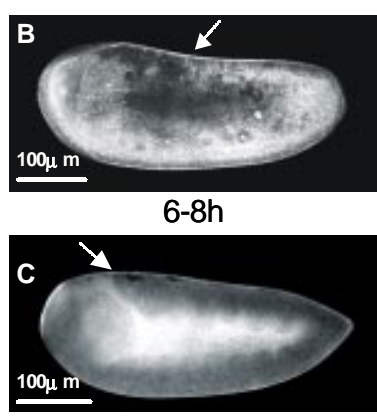

8-10h

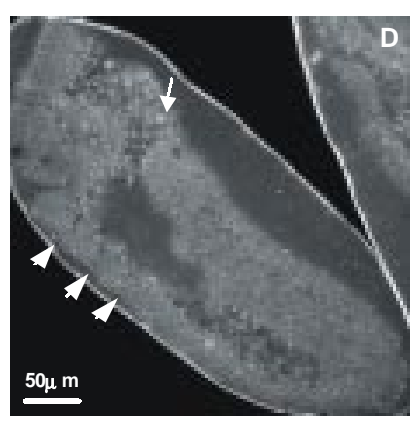

$10-12 \mathrm{~h}$
Fig. 5: germ band extension of Drosophila melanogaster (A, scanning electron microscopy) and Anopheles albitarsis (B, C, D, confocal microscopy) embryos. Arrows (B, C, D) indicate the posterior end of the germ band. Arrowheads in D point to the first external signs of segmentation, at the anterior portion of the $A n$. albitarsis embryo. Numbers below panels refer to the age of the embryos, as stated in Fig. 2. In A-C dorsal side faces upward and the anterior pole is turned to the left. dering the segments more and more visible throughout the embryo body (compare Figs 6B-D). The germ band posterior tip can be detected at 45 and $30 \% \mathrm{EL}$ at, respectively, 14-16 h (Figs 6B, 6C) and 16-18 h (Fig. 6D) of development. During this phase the stomodeum, that will give rise to the anterior gut, is clearly visible at the ventral side of the anterior pole (arrowhead on Fig. 6C). The ventral nerve cord invagination occurring in the embryo trunk is also identified, appearing as a more intensely fluorescent longitudinal stripe, when the embryo is at a dorso-lateral (Fig. 6C) or dorsal (Fig. 6D) position.

Extraembryonic membranes surround the whole mosquito embryo body and can be observed during this phase, when the embryo is completely detached from the egg chorion (at the dorsal side - Figs 6B, C, anterior - Figs 6B$\mathrm{D}$, and posterior - Figs $6 \mathrm{~B}, \mathrm{D}$ - poles).

In An. albitarsis, the $180^{\circ}$ rotation movement along the longitudinal axis, typical of mosquito embryos, takes place during the germ band retraction phase. This can be deduced if the embryo position related to the eggshell is compared in Figs 5 and 6: during germ band extension (Fig. 5), the ventral side of the embryo is adjacent to the ventral (rounded) side of the eggshell, which corresponds to its original position. By contrast, after completion of the germ band retraction the rotation movement is complete and the embryo ventral domain then faces the flattened dorsal eggshell side (22-24 h, Fig. 6E). Embryo rotation inside the egg can also be deduced after comparison of embryo and eggshell positions in Fig. 6C-E: while the egg dorsal side (flattened) faces downwards in Fig. 6C, the embryo is in a dorso-lateral position (instead of an expected lateral position). The same is true in Fig. 6D, where the dorsal eggshell side faces upwards, while the embryo is in a dorsal position.

It has been also observed that the three thoracic segments are already partially fused at 22-24 $\mathrm{h}$ after egglaying (Fig. 6E).

Dorsal closure - In D. melanogaster, dorsal closure is characterized by extension of the dorsal epidermis primordium on either side of the embryo, leading to fusion at the dorsal midline (Fig. 7A). During this process, the amnioserosa is displaced into the embryo. In this species, dorsal closure is accompanied by involution of the embryonic head (Bate \& Arias 1993, Campos-Ortega \& Hartenstein 1997).

An. albitarsis dorsal closure begins after completion of the germ band retraction (around 22-24 h, Fig. 6E) and proceeds until, at least, $34 \mathrm{~h}$ (Fig. 7B). Similarly to Drosophila, this process starts at both ends simultaneously, and the last cells to close are those belonging to the central embryonic segments (Fig. 7C).

End of embryogenesis - When dorsal closure is complete, the intersegmental limits have extended to the dorsal side of the embryo (Fig. 8). Unlike Drosophila, the mosquito head remains individualized throughout embryogenesis. The three thoracic segments remain partially fused, while 9 abdominal segments can be identified (Fig. $8 \mathrm{~B}, \mathrm{C})$.

At the anterior tip of an old embryo several projecting structures are present that should correspond to the bristles, oral brush and antenna (Fig. 8B, C). Two lateral 


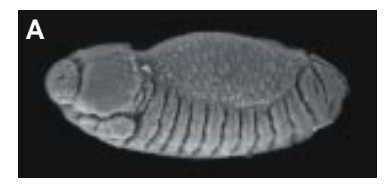

7h 20' - 10h 20'
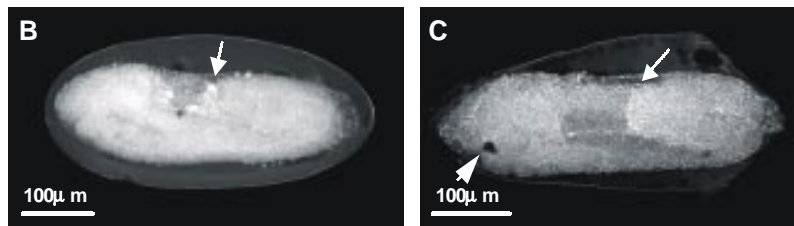

$14-16 \mathrm{~h}$

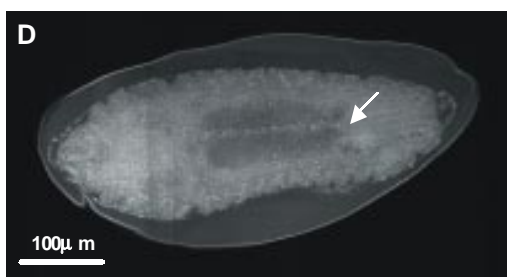

$16-18 \mathrm{~h}$

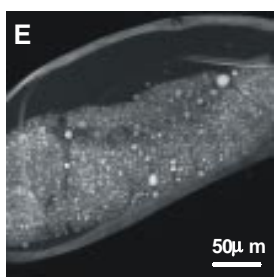

$22-24 h$
Fig. 6: germ band retraction. A: scanning electron microscopy of a Drosophila melanogaster embryo, at the end of the germ band retraction stage; B-E: confocal microscopy of Anopheles albitarsis germ band retraction embryos, progressively older. Panels B, C show embryos in a dorsolateral position, while the one in panel $\mathrm{D}$ is in a dorsal position. Other embryos (A, E) are in lateral position. Arrows (B, C, D) indicate the posterior end of the germ band. Arrowhead in $\mathrm{C}$ shows the beginning of stomodeum invagination. Numbers as in Fig. 2. In all panels the anterior pole is turned to the left side.

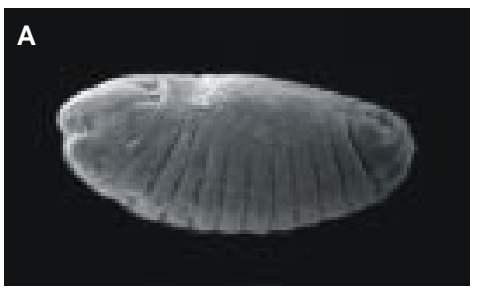

$10 \mathrm{~h} 20^{\prime}-13 \mathrm{~h}$
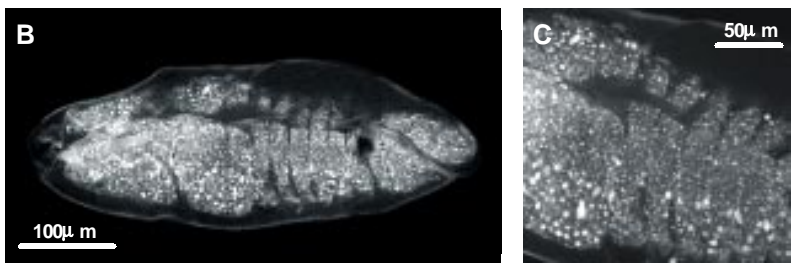

$32-34 \mathrm{~h}$

Fig. 7: dorsal closure stage of a Drosophila melanogaster (A) and Anopheles albitarsis (B, C) embryo. Note Drosophila head involution in panel A (compare with Fig. 6A). C is a detail of the central segments of the An. albitarsis embryo shown in $\mathrm{B}$, in an internal focal plane. Both embryos are in a dorsolateral position. A: scanning electron microscopy and B, C: confocal microscopy. Numbers below panels relate to the age of each embryo. In A, B, anterior pole to the left. rounded structures were identified at the dorsal side of the thorax. These internal structures, of unknown origin, appear to be of glandular nature, as judged by the presence of an empty lumen, surrounded by a single layer of large cells (data not shown). The limits between the two last abdominal segments could not be readily visualized by confocal microscopy. The posterior end of the embryo contains four elongated structures, two in lateral position and two at the tip of the trunk. These structures, better observed at the ventral side (Fig. 8B), should correspond to the anal pads present in Culicidae larva. The limits of the embryonic gut could be detected at the dorsal side (Fig. 8C).

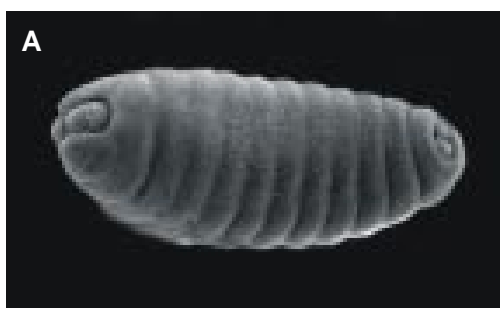

$13 \mathrm{~h}$ - eclosion $(\sim 22 \mathrm{~h})$
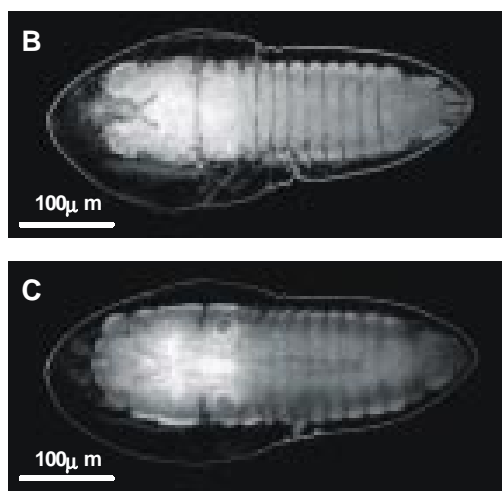

$40-42 \mathrm{~h}$

Fig. 8: end of embryogenesis of a Drosophila melanogaster (A) and an Anopheles albitarsis (B, C) embryo. A: scanning electron microscopy; B, C: confocal microscopy. A: the Drosophila embryo is in a dorsolateral position. $\mathrm{B}$ and $\mathrm{C}$ show, respectively, the ventral and dorsal sides of the same An. albitarsis embryo. Numbers below panels indicate the age of each embryo. Anterior pole to the left.

\section{DISCUSSION}

Even though An. gambiae and other Old World anophelines lead the transformation studies, analysis of their embryogeny has been neglected. Among Anopheles species, only An. maculipennis has been submitted to a morphological analysis (Ivanova-Kazas 1949). Even when other Culicidae species are concerned, morphological information on their developmental biology is limited (Rosay 1959, Davis 1967, Guichard 1971, Raminani \& Cupp 1975, 1978).

We have identified in An. albitarsis, a neotropical malaria vector, the major morphogenetic movements occurring in the course of its embryonic development. The 
present analysis, based on laser scanning confocal microscopy was possible because, after the clarification procedure, An. albitarsis embryos exhibit autofluorescence. Theoretically, the tomographic optic sections generated by confocal microscopy should reveal the whole embryo, enabling the description of internal structures. However, the fluorescence emanating from external tissues was very intense and masked the signal derived from internal domains in the wholemounts utilized, thus restricting our observations mostly to the external morphology of the embryos.

D. melanogaster, the major developmental biology model system, was used for comparison, and our analysis was based on Campos-Ortega and Hartenstein's (1997) descriptions and timing. Several major conserved events could be identified during An. albitarsis embryogenesis: blastoderm, gastrulation, germ band extension, germ band retraction and dorsal closure.

It is usually considered that timing of mosquito embryo phases is proportionally equivalent to those from Drosophila. Accurate measurements of each An. albitarsis embryonic event could not be performed due to the difficulty in obtaining synchronized egglayings for periods of time shorter than $2 \mathrm{~h}$. Nevertheless, the approximate duration of each morphogenetic event in $A n$. albitarsis was expressed as the proportion of the total embryogenesis process and compared to similar ratios in Drosophila (Table). It was observed that, in spite of current assumptions, not all events are readily comparable in both species: while timing of early embryogenesis (until germ band extension) is equivalent in both species, later events (germ band retraction and dorsal closure) take longer in An. albitarsis.

In An. albitarsis preblastoderm embryos, rounded patches exhibiting little fluorescence are supposed to correspond to syncytial energids migrating to the periphery of the embryo or, alternatively, to the embryo nuclei themselves: related to the cell's size, Anopheles early embryo nuclei are unusually large (data not shown).

TABLE

Comparison of the time elapsed, since egglaying, until the end of each major morphogenetic event in Drosophila melanogaster and Anopheles albitarsis

\begin{tabular}{|c|c|c|}
\hline & $\begin{array}{l}\text { D. melanogaster } \\
\left(\mathrm{h}^{b} / \%^{c}\right)\end{array}$ & $\begin{array}{l}\text { An. albitarsis } \\
\left(\mathrm{h}^{b} / \%^{c}\right)\end{array}$ \\
\hline Blastoderm & 2 h $50^{\prime}(13 \%)$ & \multirow{2}{*}{$4-6 \mathrm{~h}(\sim 14 \%)$} \\
\hline Gastrulation & $(14 \%)$ & \\
\hline Germ band extension & 7 h $20^{\prime}(33 \%)$ & $6-12 \mathrm{~h}(\sim 29 \%)$ \\
\hline Germ band retraction & 10 h $20^{\prime}(47 \%)$ & $12-24 \mathrm{~h}(\sim 57 \%)$ \\
\hline Dorsal closure & $13 \mathrm{~h} \quad(59 \%)$ & $24-(36) \mathrm{h}(\sim 86 \%)$ \\
\hline
\end{tabular}

a: D. melanogaster data (at $25^{\circ} \mathrm{C}$ ) derive from Campos-Ortega and Hartenstein (1997); $b$ : numbers correspond to the amount of time elapsed since egglaying until the end of each stage; $c$ : numbers in parenthesis show the approximate proportion of development until the end of each stage, related to the total embryogenesis, considering 22 and $42 \mathrm{~h}$ for, respectively, D. melanogaster and An. albitarsis.
According to Ivanova-Kazas (1949), yolk granules of An. maculipennis early embryos are spherical bodies of varying sizes. A. aegypti yolk was described as large yolk spheres in the interior of the egg plus smaller ones primarily concentrated at the periphery (Raminani \& Cupp 1975). Many yolk granules embedded in a sparse reticulum were observed in C. fatigans (Davis 1967). In $C$. pipiens big yolk granules are arranged in a compact mass that does not reach cytoplasm during migration of cleavage nuclei to the embryo cortex (Guichard 1971). Accordingly, An. albitarsis yolk sometimes appears as a homogeneous autofluorescent mass when analyzed by confocal microscopy, as judged by micrographs obtained from syncytial blastoderm (Fig. 2) and germ band extension (Fig. 5C). However, on other occasions, the yolk mass is transparent to the laser, putting the embryo itself in evidence (Figs 5B, D and 6). The intensely fluorescent small dots present in preblastoderm embryos are not supposed to correspond to yolk granules, as they have been also observed in the cortical region. Additionally, identical dots are seen in the embryo domain, but not in the yolk mass, of later stages (Figs 6E, 7B, C).

In D. melanogaster blastoderm embryos, the pole cells, precursors of germ lineage, are the first cells to be formed $\left(65-80^{\prime}\right.$ at $\left.25^{\circ}\right)$. These cells, located in the posterior pole, are larger than those from the somatic lineage and protrude outside the embryo, being easily identified (Bate \& Arias 1993, Campos-Ortega \& Hartenstein 1997). Germ lineage formation in C. pipiens and A. aegypti has been first detected in $4 \mathrm{~h}$ old embryos (Guichard 1971, Raminani \& Cupp 1975) while C. fatigans pole cells are formed between 2 h 15' and 2 h 30' (Davis 1967). Although An. albitarsis pole cells were first observed at 4-6 $\mathrm{h}$ after egglaying, the time intervals utilized in the present analysis prevented the precise timing of the germ lineage primordium formation, related to the somatic cells. In spite of that, it was verified that, unlike Drosophila, An. albitarsis blastoderm cells located at the posterior embryo tip do not protrude outside the embryo. The assignment of these cells as germ lineage precursors was due to their larger size, confirmed by confocal measurements along the embryo (some examples are illustrated in Fig. 3), together with their posterior location. In a similar way, An. maculipennis pole cells do not budge outside the embryo during blastoderm, yet they are larger than their somatic counterparts. This situation contrasts with observations on C. fatigans (Davis 1967), C. pipiens (Guichard 1971), A. aegypti (Raminani \& Cupp 1975) and An. gambiae (Valle et al. unpublished data), where budging of pole cells is evident.

Ivanova-Kazas (1949) recorded 20-30 pole cells in An. maculipennis blastoderm embryos, which is similar to the 24 germ lineage cells observed for $D$. melanogaster (Bate \& Arias 1993). In C. fatigans, C. pipiens and A. aegypti, around 15 pole cells have been estimated (Davis 1967, Guichard 1971, Raminani \& Cupp 1975). Although we did not try to systematically count pole cells, An. albitarsis blastoderm embryos do not seem to deviate from this picture (Fig. 3C).

An. maculipennis embryos kept at $22^{\circ} \mathrm{C}$ attain the syncytial blastoderm stage $5 \mathrm{~h}$ after egglaying (Ivanova-Kazas 
1949). In contrast, 2-4 h old An. albitarsis embryos have already been observed at blastoderm. Although differences in temperature, known to greatly affect the development of mosquito embryos (Ivanova-Kazas 1949, Rosay 1959, Clements 1992) could be the origin of such discrepancies, it should be taken into account that the timing of blastoderm formation is typical of the species concerned. Accordingly, $C$. fatigans embryos reach the blastoderm stage at $4 \mathrm{~h} 30^{\prime} \mathrm{h}$ at $25^{\circ} \mathrm{C}$ (Davis 1967), while A. aegypti takes longer even at higher temperatures $\left(6 \mathrm{~h}\right.$ at $27.5^{\circ} \mathrm{C}$, Raminani \& Cupp 1975).

In our analysis very few embryos could be detected at gastrulation, and those were confined to the 4-6 $\mathrm{h}$ interval. This corroborates the assumption that gastrulation, as seen in Drosophila, is a short stage in An. albitarsis. In contrast, $C$. pipiens gastrulation lasts at least $1 \mathrm{~h}$ (Guichard 1971). In another example of the species specificity of the embryonic development timing, A. aegypti gastrulation does not start before $11 \mathrm{~h}$ after egglaying (Raminani \& Cupp 1975).

Similarly to Drosophila, germ band extension in An. albitarsis embryos proceeds through a rapid early phase and a slow late phase. In D. melanogaster, the first morphological signs of segmentation appear, along the whole trunk, at maximal germ band extension (Campos-Ortega \& Hartenstein 1997). Accordingly, in An. albitarsis, these signs were first identified in 10-12 h old embryos, when germ band extension is maximal. In contrast to Drosophila, however, at that time, only the anterior portion of An. albitarsis embryo trunk seems segmented (Fig. 5D). Nevertheless, An. albitarsis embryos that have just reached the maximal germ band extension (8-10 h old) show a metameric organization of the mesoderm along the whole trunk (Fig. 5C), pointing to the simultaneous delimitation of all segments, one key feature of embryos of the long germ band type (Patel 1994).

The transverse furrows detected during gastrulation of germ band elongation in other mosquito species (Ivanova-Kazas 1949, Rosay 1959, Davis 1967, Guichard 1971) were not observed in An. albitarsis, probably because the intense fluorescence emanating from the embryos masked details of their external morphology. In Drosophila embryos, these transverse furrows are seen as a consequence of modifications in the outer cell layer, occurring during elongation of the germ band (CamposOrtega \& Hartenstein 1997). In this species the transverse furrows, that later flatten in the amnioserosa, are unrelated to the embryo segmentation. It is not probable that these grooves are the first signs of segmentation in mosquitoes, as it has been claimed earlier (Ivanova-Kazas 1949): in C. tarsalis, C. fatigans and C. pipiens transverse furrows disappear successively, from posterior to anterior, as the germ band elongates (Rosay 1959, Davis 1967, Guichard 1971).

Drosophila amnioserosa, the extra-embryonary membrane, is confined to the dorsal embryo side (Fig. 6A). In opposition, An. albitarsis shares the more typical insect pattern, being completely surrounded by extraembryonary membranes. In An. maculipennis, C. fatigans and $A$. aegypti, extra-embryonary membranes covering the entire egg contents were also noted (Ivanova-Kazas 1949, Davis 1967, Raminani \& Cupp 1975).

Detachment of the embryo from the egg starts during germ band extension, and anticipates the $180^{\circ}$ rotation movement of the embryo along its longitudinal axis, occurring during germ band retraction (Fig. 6). This movement, already noted in An. albitarsis (Valle et al. 1999) occurs in other lower Diptera embryos, but not in Drosophila (Ivanova-Kazas 1949, Rosay 1959, Guichard 1971, Clements 1992, Campos-Ortega \& Hartenstein 1997). As stated before (Valle et al. 1999), this rotation, that changes the original embryo orientation related to the eggshell, gave rise to a conceptual error in the assignment of dorsal and ventral egg sides by more recent authors. We consider that the terminology describing mosquito eggshell orientation shall take into account the original embryo position, in order to be in accordance with the primary events that occur during embryo polarity definition. For this reason the convex egg side is called ventral, while the flattened deck is seen as the dorsal side.

Three distinct aspects are morphologically distinct during An. albitarsis germ band retraction: (1) development of the ventral nerve cord, that appears as a large internal projection when the embryo is observed from the dorsal side; (2) invagination of the stomodeum, that will give rise to part of the anterior gut; and (3) the external fusion of the three thoracic segments, that is kept until hatching, being responsible for the unified aspect of mosquito larvae thorax. In D. melanogaster, both ventral nerve cord segregation and stomodeum invagination begin earlier, during germ band extension (Bate \& Arias 1993, Campos-Ortega \& Hartenstein 1997). It is possible that these events have taken place earlier in An. albitarsis, without being noticed. Accordingly, ventral nerve cord and stomodeum formation have been detected during germ band extension in An. maculipennis and in C. fatigans (Ivanova-Kazas 1949, Davis 1967). Invagination of the stomodeum was also observed during germ band extension in C. pipiens (Guichard 1971). Fusion of the thoracic segments does not occur during Drosophila embryogenesis. In mosquito embryos it has been observed during germ band retraction in An. maculipennis (Ivanova-Kazas 1949) and much later, during dorsal closure, in C. tarsalis (Rosay 1959).

In D. melanogaster, dorsal closure occurs through growing of the ectoderm towards the dorsal embryo side. When dorsal closure ends, the segmental limits are visible at the dorsal domain of the embryo. This movement proceeds from both poles and, consequently, the last segments to fuse are those located in the middle of the embryo. Similar progression of dorsal closure has also been observed not only in An. albitarsis embryos but also in other mosquito species (Rosay 1959, Davis 1967, Guichard 1971). Mosquito and Drosophila dorsal closure is distinct in two aspects: (1) the amnioserosa is internalized in Drosophila, but not in mosquito embryos and, (2) in opposition to the head involution occurring in fly embryos, resulting in larvae with an acephalous appearance, mosquito embryos and larvae head remains individualized (Bate \& Arias 1993, Campos-Ortega \& Hartenstein 1997). 
At the end of embryogenesis the embryo is clearly divided in head, thorax (with the three segments partially fused) and a segmented abdomen. Nine abdominal segments were detected, in accordance to what is described for other mosquito species (Ivanova-Kazas 1949, Rosay 1959, Davis 1967, Guichard 1971, Consoli \& Lourenço-deOliveira 1994). Two lateral internal structures are present in the dorsal side of the thorax. Although these structures could not be identified, the possibility exists that they correspond to the subesophagial ganglia as suggested to be the case with An. maculipennis (IvanovaKazas 1949).

This work aims at filling a gap on mosquito embryogenesis knowledge, necessary as a toll in further studies directed towards the control of malaria vectors. We describe the external morphology and the approximate timing of the major events occurring in the course of $A n$. albitarsis embryogenesis, using D. melanogaster as reference system. We expect that this study can contribute with the evaluation of effectiveness and risk of adopting, in the field, a vector control methodology based on the use of transgenic mosquitoes, through the phenotypic analysis of transformed mutants. Besides that, embryo morphological knowledge is at the basis of the elucidation of any gene's expression pattern in the course of development.

\section{ACKNOWLEDGEMENTS}

To Pedro Paulo de Abreu Manso for technical assistance and to the Laboratório de Análise e Processamento de Imagens, IOC-Fiocruz for helping with the figures. To Dr Adeilton Brandão for translation of the Ivanova-Kazas article.

\section{REFERENCES}

Bate M, Arias M 1993. The Development of Drosophila melanogaster, Cold Spring Harbor Laboratory Press, New York, $1558 \mathrm{pp}$.

Butler D, Maurice J, O'Brien C 1997. Time to put malaria control on the global agenda. Nature 386: 535-540.

Campos-Ortega JA, Hartenstein V 1997. The Embryonic Development of Drosophila melanogaster, 2nd ed., SpringerVerlag, Berlin, Heidelberg, 405 pp.

Catteruccia F, Nolan T, Loukeris TG, Blass C, Savakis C, Kafatos FC, Crisanti A 2000. Stable germline transformation of the malaria mosquito Anopheles stephensi. Nature 405: 959-962.

Clements AN 1992. The Biology of Mosquitoes. Development, Nutrition and Reproduction, Chapman and Hall, London, 509 pp.

Coates CJ, Jasinskiene N, Miyashiro L, James AA 1998. Mariner transposition and transformation of the yellow fever mosquito, Aedes aegypti. Proc Nat Acad Sci USA 95: 37483751.

Consoli RAGB, Lourenço-de-Oliveira R 1994. Principais Mosquitos de Importância Sanitária no Brasil, Fiocruz, Rio de Janeiro, $225 \mathrm{pp}$.

Crampton JM 1994. Approaches to vector control: new and trusted. 3. Prospects for genetic manipulaton of insect vectors. Trans R Soc Trop Med Hyg 88: 141-143.

Davis CWC 1967. A comparative study of larval embryogenesis in the mosquito Culex fatigans Wiedemann (Diptera:
Culicidae) and the sheep-fly Lucilia sericata Meigen (Diptera: Calliphoridae). I. Description of embryonic development. Aust J Zool 15: 547-579. Note Corrigendum, Aust J Zool 16: 166-168.

Forbes Z, Ingham P 1993. Drosophila embryos. In CD Stern, PWH Holland (eds) Essential Developmental Biology, A Practical Approach, Oxford University Press, Oxford, New York, Tokyo, p. 3-20.

Greenwood BM 1997. What's new in malaria control? Ann Trop Med Parasitol 91: 523-531.

Guichard M 1971. Étude in vivo du développement embryonaire de Culex pipiens. Comparaison avec Calliphora erythrocephala [Diptera]. Ann Soc Entomol Fr 7: 325-341.

Hinton HE 1968. Observations on the biology and taxonomy of the egg of Anopheles mosquitoes. Bull Entomol Res 57: 495-508.

Horosko S, Lima JBP, Brandolini MB 1997. Establishment of a free mating colony of Anopheles albitarsis from Brazil. $J$ Am Mosq Control Assoc 13: 95-96.

Ivanova-Kazas OM 1949. [Embryonic development of Anopheles maculipennis MG.] Izvestiia Akademii Nauk Sepiia Biologicheskaia 2: 140-170.

Jasinskiene N, Coates CJ, Benedict MQ, Cornel AJ, Rafferty CS, James AA, Collins FH 1998. Stable transformation of the yellow fever mosquito, Aedes aegypti, with the Hermes element from the housefly. Proc Nat Acad Sci USA 95: 3743-3747.

Kidwell MG, Ribeiro JMC 1992. Can transposable elements be used to drive disease refractoriness genes into vector populations? Parasitol Today 8: 325-329.

Lanzara GC, Narang SK, Mitchell SE, Kaiser PE, Seawright JA 1988. Hybrid male sterility in crosses between field and laboratory strains of Anopheles quadrimaculatus (Say) (Diptera: Culicidae). J Med Entomol 25: 248-255.

Li J 1994. Egg chorion tanning in Aedes aegypti mosquito. Comp Biochem Physiol 109A: 835-843.

Miller LH, Sakai RK, Romans P, Gwadz RW, Kantoff P, Coon HG 1987. Stable integration and expression of a bacterial gene in the mosquito Anopheles gambiae. Science 237: 779781.

Monnerat AT, Soares MJ, Lima JBP, Rosa-Freitas MG, Valle D 1999. Anopheles albitarsis eggs: ultrastructural analysis of chorion layers after permeabilization. J Insect Physiol 45: 915-922.

Morel CM 2000. Reaching maturity - 25 years of the TDR. Parasitol Today 16: 522-526.

Patel NH 1994. The evolution of arthropod segmentation: insights from comparisons of gene expression patterns. Development (Suppl.): 201-207.

Raminani LN, Cupp EW 1975. Early embryology of Aedes aegypti (L.) (Diptera: Culicidae). Int J Insect Morphol Embryol 4: 517-528.

Raminani LN, Cupp EW 1978. Embryology of Aedes aegypti (L.) (Diptera: Culicidae): organogenesis. Int J Insect Morphol Embryol 7: 273-296.

Rosay B 1959. Gross external morphology of embryos of Culex tarsalis Coquillett (Diptera: Culicidae). Ann Entomol Soc Am 52: 481-484.

Trpiš M 1970. A new bleaching and decalcifying method for general use in zoology. Can J Zool 48: 892-893.

Valle D Monnerat AT, Soares,MJ, Rosa-Freitas MG, PelajoMachado M, Vale BS, Lenzi HL, Galler R, Lima JBP 1999. Mosquito embryos and eggs: polarity and terminology of chorionic layers. J Insect Physiol 45: 701-708. 